\title{
Highlights of the 16th annual scientific sessions of the Society for Cardiovascular Magnetic Resonance
}

\author{
John-Paul Carpenter ${ }^{1+}$, Amit R Patel ${ }^{2 \dagger}$ and Juliano Lara Fernandes ${ }^{3 *+}$
}

\begin{abstract}
The 16th Annual Scientific Sessions of the Society for Cardiovascular Magnetic Resonance (SCMR) took place in San Francisco, USA at the end of January 2013. With a faculty of experts from across the world, this congress provided a wealth of insight into cutting-edge research and technological development. This review article intends to provide a highlight of what represented the most significant advances in the field of cardiovascular magnetic resonance (CMR) during this year's meeting.
\end{abstract}

Keywords: Cardiovascular magnetic resonance, Heart

\section{Introduction}

This year's SCMR Annual Scientific Sessions were attended by a record number of 1427participants. The number of abstracts presented during the meeting also grew significantly from previous editions with a total of 602 abstracts being shown. Many of these new abstracts were introduced during the SCMR/International Society for Magnetic Resonance in Medicine (ISMRM) Jointly Sponsored Workshop "New Horizons in High-field Cardiovascular Imaging: Promises and Progress" as well as in the new ePosterGallery.

In this article, we have tried to cover most of the themes presented during the five days of the event summarizing the topics into technical/imaging methods and clinical applications. Throughout the meeting, the SCMR Program Committee ensured that all of the major areas of interest were covered with an invited lecture session to complement the scientific abstract presentations. All abstracts presented during the meeting can be accessed in the special supplement of the Journal of Cardiovascular Magnetic Resonance [1]. Many of the invited lectures and oral abstract sessions were recorded and are available at www.scmr.org.

\section{Review}

Details of the SCMR Gold Medal award for outstanding contribution to the field of CMR (awarded to Professor

\footnotetext{
* Correspondence: jlaraf@terra.com.br

${ }^{\dagger}$ Equal contributors

${ }^{3}$ University of Campinas, Campinas, Brazil

Full list of author information is available at the end of the article
}

Stefan Neubauer), the best oral presentations and abstract award winners for both SCMR annual scientific sessions and the SCMR/ISMRM workshop are given in Tables 1 and 2. The winning authors of the Gerald Pohost award for best Journal of Cardiovascular Magnetic Resonance (JCMR) manuscript in 2012 are shown in Table 3.

\section{Technical advances/imaging methods}

This year's SCMR/ISMRM pre-Sessions workshop focused on the development of high-field CMR, an increasing area of interest as scanners move from $1.5 \mathrm{~T}$ to $3.0 \mathrm{~T}$ and even $7.0 \mathrm{~T}$ systems $[5,6]$. Challenging problems with high field strengths currently involve the development of specific transmit/receive coils to allow assessment of $23 \mathrm{Na}-\mathrm{MRI}$ as well as CMR-spectroscopy, new imaging sequences to take advantage of the increase in signal-to-noise ratio (SNR) as well as better ways to handle ECG gating. In that regard, Ferreira et al. presented a new free-breathing navigator sequence to assess cardiac diffusion tensor imaging (DTI) at $3 \mathrm{~T}$ to characterize myocardial fiber disarray patterns as has recently been published [7-9] while Teh et al. demonstrated a new accelerated diffusion-weighted fast spin echo sequence that resulted in an 8-fold increase in acquisition time in a mouse model using 9.4 T scanning [10]. DTI was the subject of one of three plenary lectures delivered by Dudley Pennell at the opening of the main meeting (http://scmr.org/Education/CMR-online-videoon-demand-lectures/3072/3248/3252.html) - Figure 1. As mentioned above, ECG gating becomes more difficult with increasing field strength due to magnetohydrodynamic 
Table 1 16th SCMR annual scientific sessions - awards

\begin{tabular}{llll}
\hline Award & Recipient & Institution & Subject \\
\hline SCMR Gold Medal & $\begin{array}{l}\text { Professor Stefan } \\
\text { Neubauer }\end{array}$ & Oxford University & For outstanding contribution to the field of CMR \\
\hline Early career award - basic science & Behzad Sharif & Cedars-Sinai Medical Center & $\begin{array}{l}\text { Eliminating dark-rim artifacts in first-pass myocardial } \\
\text { perfusion imaging (O3) }\end{array}$ \\
\hline Early career award - translational & James Harrison & King'sCollege London & $\begin{array}{l}\text { Magnetic resonance imaging of acute and chronic atrial } \\
\text { ablation injury - a histological validation study (O18) }\end{array}$ \\
\hline Early career award - clinical & Saira Dass & The John Radcliffe Hospital & $\begin{array}{l}\text { Patients with dilated cardiomyopathy (DCM) have } \\
\text { appropriate myocardial oxygenation response to } \\
\text { vasodilator stress (O68) }\end{array}$ \\
\hline Moderated poster session 1 & Kathryn Broadhouse & Imperial College London & $\begin{array}{l}\text { Quantification of aortic pulse wave velocity in preterm } \\
\text { infants using 4D phase contrast MRI (M7) }\end{array}$ \\
\hline Moderated postersession 2 & Daniel Kuetting & Universityof Bonn & $\begin{array}{l}\text { Assessment of cardiac dyssynchrony: a comparison of velocity } \\
\text { encoded imaging and feature tracking analysis (M11) }\end{array}$ \\
\hline Best technologist abstract & Celia O'Meara & $\begin{array}{l}\text { UniversityCollege London } \\
\text { Hospitals }\end{array}$ & $\begin{array}{l}\text { Initial experience of imaging cardiac sarcoidosis using } \\
\text { hybrid PET-MR - a technologist's case study (T1) }\end{array}$ \\
\hline Best SCMR web case of the year & Rob Huggett & Russells Hall Hospital, UK & \begin{tabular}{l} 
Post pericardiectomy for constriction - a late complication \\
\hline
\end{tabular} \\
\hline
\end{tabular}

effects of the higher magnetic fields. To circumvent that problem, Krug et al. demonstrated the problems encountered with regular vectorcardiograms at 3.0 and $7.0 \mathrm{~T}$ proposing an independent component analysis alternative [11] and Tse et al. presented a new 3D-QRS method using 12lead ECG gating inside the magnet to allow for real-time gating at $3.0 \mathrm{~T}$ in patients with complex heart rates such as premature ventricular beats, atrial fibrillation and significant beat-to-beat variations [12].

\section{Increasing spatial/temporal resolution}

Many advances presented this year dealt with technical developments with the objective of increasing the spatial and/or temporal resolution of CMR images as well as decreasing image acquisition time. One major focus was how to implement new methods in order to acquire real-time non triggered images allowing much more simple and robust imaging as well as permitting the use of CMR to guide percutaneous interventions [13]. Aneja et al. demonstrated that real-time CMR using nonoptimized sequences with lower spatial and temporal resolution already derives similar results to traditional breath-held images in patients with regular cardiac rhythm [14]. Although this approach was limited to a small number of patients and using standard sequences only, the principles of real-time imaging are rapidly gaining acceptance as CMR increases its clinical utility.
With that objective in mind, an increasing number of abstracts focused on new sequences that take advantage of undersampling the k-space with spatiotemporal modeling such as compressed sensing [15] to increase current resolution limits. Using sparse and incoherent sampling with multiple iterative reconstructions Schmidt et al. showed that these new techniques provide high spatial $(2.4 \times 1.7 \times$ $6.0 \mathrm{~mm}$ ) as well as temporal resolution $(33 \mathrm{~ms})$ within 1 heartbeat acquisition in real time [16]. Introducing a new regional sparsity reconstruction method, Chen et al. also demonstrated the feasibility of compressed sensing for obtaining in vivo perfusion images, allowing for increase in ventricular coverage or spatial resolution as previous techniques have shown $[17,18]$.

Non-cartesian acquisitions have also seen a gain in use and moved from the preliminary work in coronary artery imaging to other applications in CMR [19]. Sharif et al. used an ungated radial acquisition method to acquire first-pass perfusion images simultaneously combined with cine images for assessment of perfusion and wall motion within the same scan [20]. Yang et al. also used a combination of spiral trajectories with compressed sensing to obtain full ventricular coverage during first pass perfusion with the acquisition of 8 slices in $480 \mathrm{~ms}$ with $1.75 \times 1.75 \mathrm{~mm}$ in-plane resolution allowing for heart rates up to 125 beats per minute during stress imaging [21]. In another abstract by Petersson et al. the authors

Table 2 SCMR/ISMRM workshop abstract awards

\begin{tabular}{llll}
\hline Award & Recipient & Institution & Manuscript title \\
\hline Best Oral Abstract & Gabriel Camargo & $\begin{array}{l}\text { Clinica de Diagnostico por Imagem, } \\
\text { Rio de Janeiro, Brazil }\end{array}$ & $\begin{array}{l}\text { Myocardial Iron Quantification Using Modified Look-Locker } \\
\text { Inversion Recovery (MOLLI) T1 Mapping at 3 Tesla }\end{array}$ \\
\hline Best Poster & Johannes Krug & $\begin{array}{l}\text { Otto-von-Guericke University of } \\
\text { Magdeburg }\end{array}$ & $\begin{array}{l}\text { Improved ECG Based Gating in Ultra High Field Cardiac MRI } \\
\text { Using an Independent Component Analysis Approach }\end{array}$ \\
\hline
\end{tabular}


Table 3 Gerald Pohost award for best Journal of Cardiovascular Magnetic Resonance (JCMR) manuscript in 2012

\begin{tabular}{llll}
\hline Award & Recipient & Institution & Manuscript title \\
\hline First place & Jurg Schwitter & $\begin{array}{l}\text { University Hospital, } \\
\text { Lausanne }\end{array}$ & $\begin{array}{l}\text { Superior diagnostic performance of perfusion-cardiovascular magnetic resonance } \\
\text { versus SPECT to detect coronary artery disease: The secondary endpoints of the } \\
\text { multicenter multivendor MR-IMPACT II (Magnetic Resonance Imaging for } \\
\text { Myocardial Perfusion Assessment in Coronary Artery Disease Trial). [2] }\end{array}$ \\
\hline Second place & Peter Kellman & $\begin{array}{l}\text { National Institutes of } \\
\text { Health (NIH) }\end{array}$ & $\begin{array}{l}\text { Extracellular volume fraction mapping in the myocardium, part 1: evaluation of } \\
\text { an automated method. [3] }\end{array}$ \\
\hline Third place & Choukri Mekkaoui & $\begin{array}{l}\text { Harvard Medical } \\
\text { School }\end{array}$ & $\begin{array}{l}\text { Fiber architecture in remodeled myocardium revealed with a quantitative diffusion } \\
\text { CMR tractography framework and histological validation. [4] }\end{array}$ \\
\hline
\end{tabular}

demonstrated the use of spiral k-space trajectories to acquire $4 \mathrm{D}$ flow stacks with a significant $62 \%$ reduction in scan time while maintaining similar image quality compared to traditional readout methods [22].

\section{Improving artifacts}

Another highlight of the meeting was in the developments of new methods to overcome old problems in CMR such as dark rim artifacts, off-resonance effects and banding [23]. The Early Career Award in Basic Sciences was awarded to Sharif et al. for an abstract that proposed to reduce dark-rim artifacts during first-pass perfusion by using a single-shot radial sequence in comparison to the routine Cartesian technique with a significant decrease in both artifact score as well as in its maximum width (Figure 2) [24]. Problems with $3 \mathrm{~T}$ MRI were also addressed by $\mathrm{Wu}$ et al. who proposed a shorter TR for SSFP cine imaging through a reduced RF pulse duration and readout showing that the new approach resulted in images more robust to field in homogeneity at this higher field strength with minimum reduction in spatial resolution while allowing for elimination of frequency scouts and more rapid breath-hold times [25]. Another way to improve susceptibility artifacts without the need to use time consuming frequency adjustments was presented by Rothstein et al. who proposed a new 3D shimming algorithm which resulted in similar results for volumes and function evaluation keeping the same levels of banding artifacts as frequency offsets but with a more simplified workflow [26].

\section{T1 Mapping sequence developments}

With the rapidly increasing body of new clinical data on T1 mapping, more understanding of the fundamental principles of the sequences used to generate these maps is essential [27]. A comprehensive series of lectures on T1 mapping in the heart was presented by Peter Kellman, Martin Ugander, Erica Dall' Armellina and Andrew Flett (http://scmr.org/Education/CMR-online-video-on-demandlectures/3072/3151/3154.html). This provided a clear explanation of the pros and cons of each of the different sequences together with the importance of both accuracy and precision of measurement. The potential clinical applications of T1 mapping including the measurement of extracellular volume fraction to visualize the extent and severity of abnormalities within the myocardium were outlined in detail.

Almost $10 \%$ of the submitted abstracts for the meeting involved T1 mapping. Many sessions discussed the current use of T1 maps and the need to standardize and optimize the acquisition techniques to pre- and post-contrast maps, the use of bolus versus continuous infusion of gadolinium as well as the different approaches to heart rate variability and types of sequences. Fitts et al. presented a recent

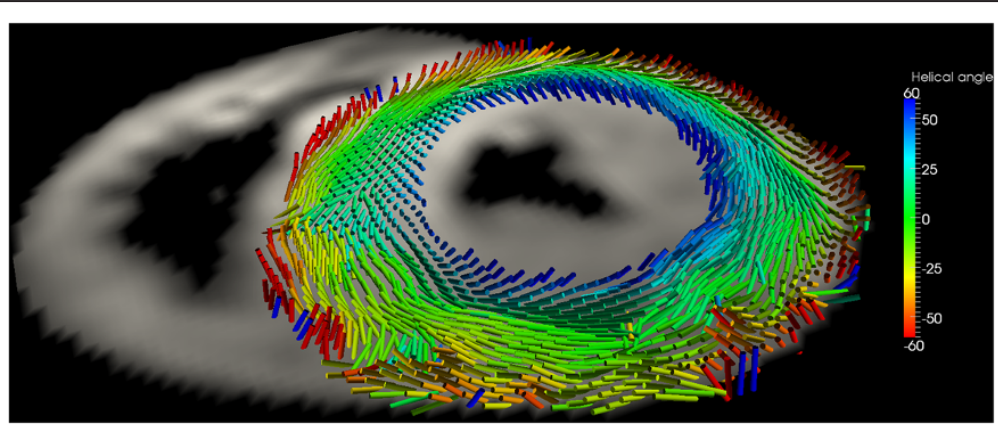

Figure 1 Diffusion tensor imaging in the basal short-axis plane in a patient with hypertrophic cardiomyopathy. The acquisition used a diffusion-weighted stimulated-echo single-shot echo-planar-imaging sequence during multiple breath holds. The tensor's main eigenvector, which follows the orientation of the myocytes, is represented by cylindrical glyphs, colour coded according to the helix angle: blue right-handed, green circumferential, red left-handed (Image courtesy of Pedro Ferreira and Dudley Pennell). 

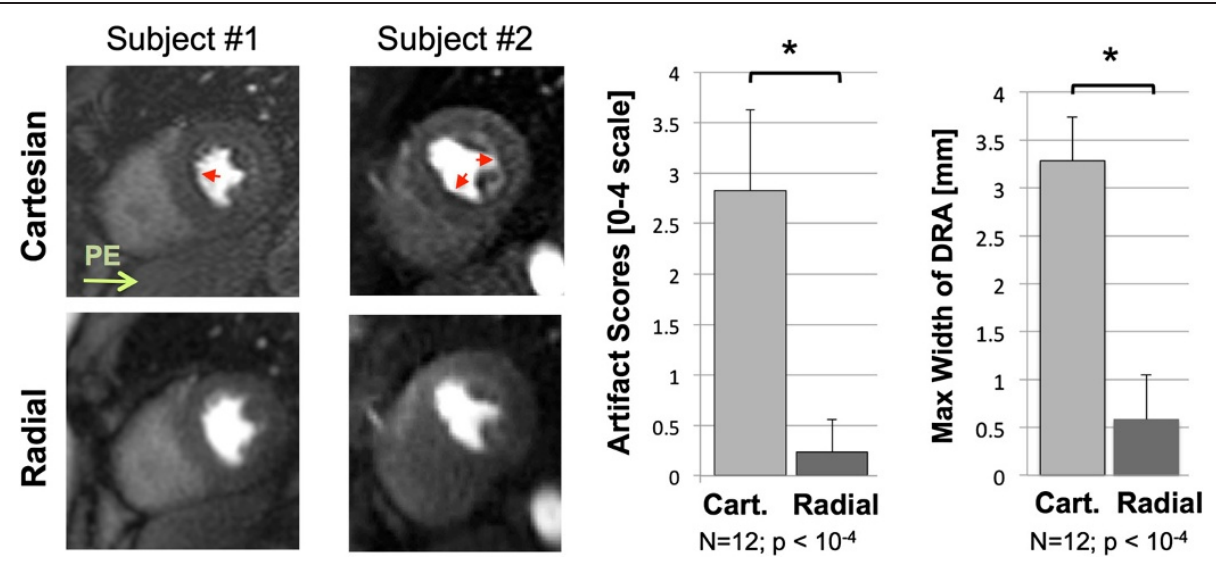

Figure 2 Elimination of dark rim artifact on first-pass perfusion imaging using radial k-space trajectory. The left hand panel shows examples of first pass perfusion images in two subjects. The artifact seen in the phase encode (PE) direction with Cartesian trajectory (top row) is eliminated with radial $k$-space filling (bottom row). The histograms reveal a significant reduction in artifact scores (on a scale of 1-4) and maximum width of dark rim artifacts (DRA) with the radial technique (Sharif et al., abstract O3).

arrhythmia-insensitive rapid T1 mapping sequence to overcome some of the limitations of the most widely used modified Look-Locker inversion recovery (MOLLI) techniques [28]. The sequence is based on saturation recovery magnetization and uses centric k-space ordering resulting in smaller coefficients of variation and higher T1 values in patients with high heart rates or arrhythmias. In another study using phantoms, Slavin et al. also showed that using a saturation recovery pulse but with a balanced SSFP readout they could find more accurate T1 values compared to MOLLI due to its insensitivity to beat-to-beat variations and lack of T2 dependence [29]. In a comparison of different sequences including the classical MOLLI sequence, a shortened (sh)MOLLI acquisition with 9 heartbeats [30], a 3'5 MOLLI and a saturation recovery single shot acquisition sequence (SASHA) the authors reported that the 3'5 MOLLI sequence was more closely associated to the original MOLLI T1 values compared to the two other sequences while the shMOLLI technique underestimated T1 values by $13 \%$ and the SASHA sequence overestimated the T1 values by $17 \%$. Finally, a 3D technique acquired with free breathing was also presented by Henningsson et al. with the average scan time of 9:37 minutes to cover the whole left ventricle with a resolution of $1.5 \times 1.5 \times 8 \mathrm{~mm}^{3}$ using SASHA resulting in an increase in SNR compared to 2D-SASHA images with similar T1 values [31].

\section{Developments in vascular imaging}

The development of rapid prototyping (or 3D printing) has allowed highly accurate models of vascular structures to be generated [32]. Acevedo-Bolton et al. described how complex intracranial aneurysms imaged with magnetic resonance could be recreated in order to test the effectiveness of flow-diverting stents [33]. This work not only enables the operator to gain valuable experience on a 'dry run' but allows assessment of the preand post-procedure flow dynamics using 4D flow.

Three other oral presentations described the utility of the quiescent-interval single shot or 'QISS' sequence for non-contrast MR angiography. The technique (with various alterations including radial vs. Cartesian geometry k-space acquisition) shows excellent performance and correlates very well with contrast exams in patients with peripheral arterial disease. These angiographic techniques have the potential to be combined with more functional assessment (such as rest and stress calf perfusion) to assess ischemia and response to treatment [34]. ClementGuinaudeauet al presented data on a calf muscle perfusion index which correlated very well with peak walking time and claudication onset time [35]. Using a simple MRcompatible device to allow exercise stress in the scanner bore, this has useful potential as a surrogate endpoint for clinical trials.

\section{Implementation of CMR into routine clinical practice}

In addition to many technical developments, this year's SCMR also featured several presentations showing the central role of CMR in the management of the cardiovascular patient. One of the strengths of this year's conference was the introductory talk given by an expert in the field at the start of each of the oral abstract sessions. Raymond Kwong succinctly summarized the available evidence from the last 25 years on how the development of CMR has helped diagnosis, determine prognosis and provide an impact on diagnostic thinking, therapeutic actions and patient outcomes. Anya Wagner presented the most recent results of the EuroCMR registry covering 27,000 patients from 57 European centers [36]. This 
has cemented CMR at the center of diagnostic imaging in Europe, proving that it is feasible and safe with $62 \%$ of the scans performed having an impact on patient management, the most common indication being for risk stratification in coronary artery disease. Florian Andre presented data from a cohort of more than a 1000 patients showing that measuring left ventricular ejection fraction by CMR reclassified many patients into different risk groups when compared to echocardiography [37]. Others have shown the potential clinical impact of more accurate measurement of ejection fraction by CMR on selecting patients who might benefit from defibrillator implantation [38]. Recently, it has been demonstrated that the addition of late gadolinium enhancement CMR adds further prognostic value over echocardiography alone [39]. Additionally, it is becoming increasingly recognized that using CMR in a cost-effective way can provide potential savings for healthcare providers [40].

\section{Ischemic heart disease}

With the publication of CE-MARC [41] and MRIMPACT 2 [2] vasodilator stress CMR has been shown in prospectively designed studies to be a reasonable alternative to stress single-photon emission computed tomography (SPECT) for the detection of significant coronary artery disease. It has additionally been shown that performing stress CMR to identify patients who benefit from coronary angiography offers significant savings when compared to directly performing coronary angiography. John Greenwood adds to this by presenting new data from the CE-MARC trial suggesting that strategies the utilize stress CMR first followed by invasive coronary angiography if the CMR study is abnormal or inconclusive may be more cost-effective when compared to a SPECT first strategy [42]. Similarly, Sebastian Kelle showed the cost-effectiveness of strategies for the assessment of stable coronary artery disease that utilize dobutamine stress to identify patients who might benefit from a coronary angiogram rather than sending all patients directly to cardiac catheterization [43]. Using a Markov analysis, Steffen Petersen presented data suggesting that the cost-effectiveness of a diagnostic strategy was dependent on the pretest probability of having coronary artery disease. His analysis suggested stress CMR strategies were most cost effective in patients with a higher pretest probability and that cardiac computed tomography strategies were more cost-effective in patients with a low to intermediate pretest probability [44].

An important limitation of stress CMR is the incomplete coverage of the left ventricle and may prevent adequate assessment of ischemic burden. Sven Plein compared the ischemic and scar burden as determined by a standard clinical stress CMR technique to SPECT [45]. He found that CMR measures significantly less scar but more ischemia than SPECT possibly due to the incomplete coverage of perfusion CMR. In a prospective, multicenter trial, Robert Manka showed that whole heart, three-dimensional myocardial perfusion imaging (Figure 3 ) correlated highly with fractional flow reserve [46].It remains to be seen whether such a technique will improve the quantification of ischemic burden and whether the burden of ischemia as measured by CMR can identify patients who will benefit from revascularization in addition to aggressive medical therapy alone.

\section{Non-ischemic heart disease}

The role of CMR in the assessment and risk stratification of non-ischemic heart disease is well established

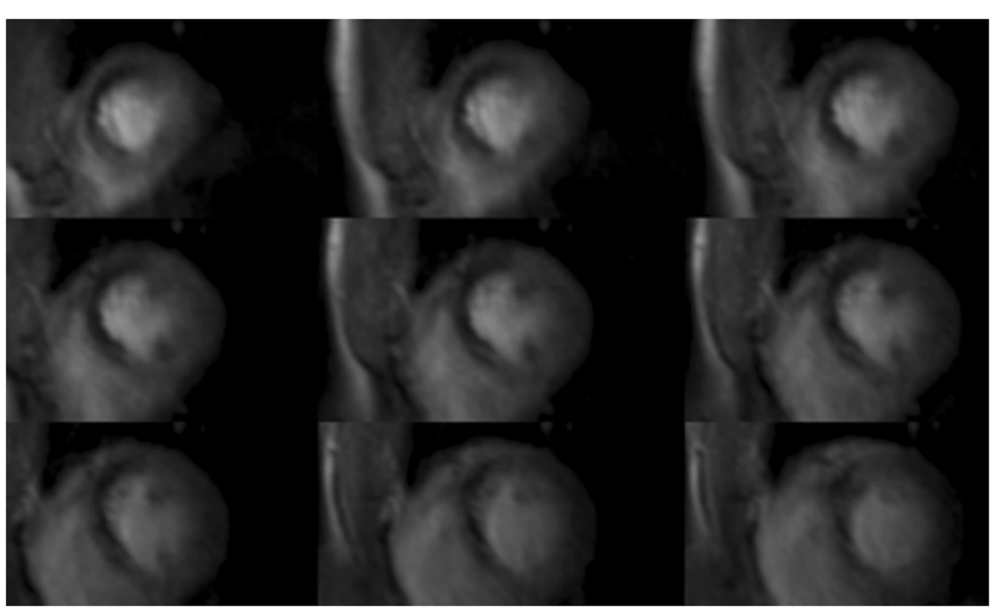

Figure 3 3D CMR perfusion scan during adenosine infusion showing an inducible perfusion defect in the anterior and anteroseptal walls extending from the base to the apex. Invasive coronary angiography identified a high-grade stenosis in the left anterior descending artery (Manka et al., abstract 0103). 
[47]. Currently available data detail the ability of CMR to risk stratify patients with a variety of non-ischemic heart diseases such as dilated cardiomyopathy, myocardial siderosis, and hypertrophic cardiomyopathy (HCM) [48]. However, large outcome studies remain challenging. Ismail et al. presented data on 711 consecutive patients with HCM with a total of 2852 patient-years of follow-up [49]. Although the amount of fibrosis was a significant univariate predictor of sudden cardiac death risk, on multivariate analysis, only left ventricular ejection fraction remained a significant predictor. The understanding of the HCM phenotype is becoming ever more complex [48,50]. Deva explained the incremental predictive value of inferoseptal crypts [51] and Flett proposed a previously unrecognized pattern of relative apical hypertrophy which may be an early form of HCM as the group found many features of HCM in patients with unexplained T-wave inversion [52]. Christopher Kramer unveiled the details of a proposed large scale, multiparametric, multicenter, observational registry with the goal of better defining the role of CMR in the risk stratification of the HCM patient.

As previously mentioned, T1 mapping featured highly throughout the sessions. Sado et al. presented findings of low pre-contrast T1 values in Anderson-Fabry disease and iron overload which may help to define pre-clinical phenotypes more accurately [53]. Whereas the assessment of diastolic function has traditionally been cumbersome and time-consuming with CMR, Simpson et al. have developed a new high spatial and temporal resolution tissue phase contrast technique which allows much shorter acquisitions and brings this nearer to clinical prime-time [54]. In an invited lecture, Michael Markl reviewed promising techniques such as tissue phase mapping with respiratory navigator gating, 2-dimensional and 3-dimensional Displacement Encoding with Stimulated Echoes (DENSE), and strain encoded imaging (SENC) for assessing myocardial mechanics and quantifying the various components of myocardial strain (http://scmr.org/Education/CMR-onlinevideo-on-demand-lectures/3072/3157/3160.html). During the same session, Alicia Maceira, Amit Patel, and Sophie Mavrogeni suggested that CMR with late gadolinium enhancement imaging plays an important role for the detection of cardiac involvement and risk stratification of patients with systemic disorders such as amyloidosis, vasculitis, and other rheumatologic disorders such as systemic lupus erythematosis, sarcoidosis, rheumatoid arthritis, and systemic sclerosis (http://scmr.org/Education/CMR-onlinevideo-on-demand-lectures/3072/3157/3161.html).

\section{CMR and electrophysiology}

Francisco Leyva reviewed the role of CMR for identifying patients that may benefit from defibrillator implantation and resynchronization therapy (http://scmr.org/Education/
CMR-online-video-on-demand-lectures/3072/3163/3164. html). Several investigators have shown that the extent of late gadolinium enhancement is strongly associated with need for future ICD therapy [55]. The burden of late gadolinium enhancement is also associated with likelihood of responding to resynchronization therapy; in fact, using late gadolinium enhancement images to guide left ventricular lead placement improves outcomes following biventricular pacing [56].

The continued development of real-time imaging for interventional CMR procedures is an important area of research. Tse et al presented preliminary animal data on a voltage-based electroanatomic tracking system which can be used to measure intracardiac electrograms both in and out of the scanner bore, including during imaging sequences. Radiofrequency signals from patches on the skin allow the operator to track the navigation of a catheter tip without the need for co-registration [57]. Ramanan et al. went on to describe how catheter ablation lesions could be mapped acutely using a combination of T2 and $\mathrm{T} 1$ * mapping with late gadolinium enhancement [58]. This has the potential for verifying the effectiveness of ablation by differentiating the actual lesion area from surrounding oedema. On a different subject, Ainslie et al. reported interim data from the multiparametric CMR assessment on RV apical versus septal pacing study (MAPS)which aims to determine the optimal site for right ventricular pacing using CMR, echo, cardiopulmonary exercise testing and biomarkers [59]. Patients with persistent atrial fibrillation requiring AV node ablation and permanent pacemaker implants were fitted with an MR-conditional St. Jude pacemaker and two RV endocardial leads placed at the RV apex and in the septum (one in the ventricular port and one in the atrial port of the device). Using a crossover study design with ventricular pacing at each of the sites, CMR measurements were taken at three time points. Early results have shown that not only is cardiac scanning safe in these patients but that there is higher aortic and pulmonary flow as well as less dyssynchrony with septal pacing.

\section{Congenital heart disease}

CMR continues to show its superiority over other imaging modalities in the field of congenital cardiovascular disease. This year cases for one of the congenital heart case review sessions were competitively selected from open competition with blind and independent ratings from several expert reviewers. The resultant session was popular, interactive and of high quality. The benefits of CMR in congenital heart disease, not least with regards accurate anatomical delineation, were well illustrated. In addition, refinements in flow imaging are improving our understanding not only in complex congenital disease but also in more routine cases. Muzzarelli et al. presented 
their data on the optimal measurement of aortic flow in bicuspid aortic valve disease [60] and Hart et al. demonstrated how 4D flow can give a much greater insight into the understanding of haemodynamics of the Fontan circulation during the breathing cycle [61]. Although acquisitions can be long and complex post-processing is required, $4 \mathrm{D}$ flow techniques have the potential to develop into a useful clinical tool [62].

\section{Case presentations}

As in previous years, a highly popular component of the program involved a series of 10 case review sessions, each discussing a range of interesting cases including complex, challenging problems and more mundane day-to-day cases. A lively, interactive debate was generated between delegates and experts in the field. The SCMR website publishes a regular featured 'case of the week' and the best 5 of these cases from 2012 were presented in full (http://scmr.org/ caseoftheweek.html).

\section{Conclusions}

In conclusion, the 2013 SCMR Scientific Sessions has consolidated a now long track record of successful meetings positioning CMR as a robust and prominent option in cardiovascular imaging. The technical advances highlighted here and the clinical applications ready to be implemented in daily routine presented at the meeting demonstrate that the method has never been so relevant and promising, with a continuous increase in the number of manuscripts published as well as a rising number of practitioners. SCMR deserves much recognition for this accomplishment and its meeting is certainly a reflection of that success.

\section{Competing interests}

The authors declare that they have no competing interests.

\section{Authors' contributions}

JLF conceived the study and participated in the design, data collection and draft of the manuscript. JPC and ARP participated in the design, data collection and draft of the manuscript. All authors read and approved the final manuscript.

\section{Author details}

${ }^{1}$ Royal Brompton Hospital, London, UK. ²University of Chicago, Chicago, USA.

${ }^{3}$ University of Campinas, Campinas, Brazil.

Received: 3 March 2013 Accepted: 13 June 2013

Published: 19 July 2013

\section{References}

1. Pennell DJ. Abstracts of the 16th annual SCMR scientific sessions. J CardiovasC Magn Reson. 2013; 15(Suppl 1):1-481.

2. Schwitter J, Wacker CM, Wilke N, Al-Saadi N, Sauer E, Huettle K, Schonberg SO, Debl K, Strohm O, Ahlstrom H, et al. Superior diagnostic performance of perfusion-cardiovascular magnetic resonance versus SPECT to detect coronary artery disease: the secondary endpoints of the multicenter multivendor MR-IMPACT II (magnetic resonance imaging for myocardial perfusion assessment in coronary artery disease trial). J Cardiovasc Magn Reson. 2012; 14:61.

3. Kellman P, Wilson JR, Xue H, Ugander M, Arai AE. Extracellular volume fraction mapping in the myocardium, part 1 : evaluation of an automated method. J Cardiovasc Magn Reson. 2012; 14:63.
4. Mekkaoui C, Huang S, Chen HH, Dai G, Reese TG, Kostis WJ, Thiagalingam A, Maurovich-Horvat $P$, Ruskin JN, Hoffmann $U$, et al. Fiber architecture in remodeled myocardium revealed with a quantitative diffusion CMR tractography framework and histological validation. J Cardiovasc Magn Reson. 2012; 14:70.

5. Oshinski JN, Delfino JG, Sharma P, Gharib AM, Pettigrew RI. Cardiovascular magnetic resonance at 3.0 T: current state of the art. J Cardiovasc Magn Reson. 2010; 12:55.

6. Snyder CJ, DelaBarre L, Metzger GJ, van de Moortele PF, Akgun C, Ugurbil K, Vaughan JT. Initial results of cardiac imaging at 7 Tesla. Magn Reson Med. 2009; 61:517-24

7. Nielles-Vallespin S, Mekkaoui C, Gatehouse P, Reese TG, Keegan J, Ferreira PF, Collins S, Speier P, Feiweier T, de Silva R, et al. In vivo diffusion tensor MRI of the human heart: reproducibility of breath-hold and navigator-based approaches. Magn Reson Med. 2012; 12:17.

8. McGill LA, Ismail TF, Nielles-Vallespin S, Ferreira P, Scott AD, Roughton M, Kilner PJ, Ho SY, McCarthy KP, Gatehouse PD, et al. Reproducibility of in-vivo diffusion tensor cardiovascular magnetic resonance in hypertrophic cardiomyopathy. J Cardiovasc Magn Reson. 2012; 14:86.

9. Ferreira PJ, Nielles-Vallespin S, Gatehouse PD, de Silva R, Keegan J, Speier P, Feiweier T, Reese TG, Ismail TF, Scott A, et al. Cardiac diffusion tensor imaging: helix angle (HA) healthy statistical average technique for $\mathrm{HA}$ quantification in vivo. J Cardiovasc Magn Reson. 2013; 15(suppl 1):W7.

10. Teh I, Lohezic M, Aksentijevic D, Schneider JE. Accelerated fast spin echo diffusion spectrum imaging in the mouse heart ex-vivo. J Cardiovasc Magn Reson. 2013; 15(suppl 1):W6.

11. Krug JW, Rose G, Stucht D, Clifford G, Oster J. Limitations of VCG based gating methods in ultra high field cardiac MRI. J Cardiovasc Magn Reson. 2013; 15(suppl 1):W19.

12. Tse Z, Dumoulin C, Watkins R, Butts Pauly K, Kwong RY, Michaud GF, Stevenson W, Joslesz F, Schmidt EJ. Improved cardiac gating at 3T with the "3D-QRS" method utilizing MRIcompatible 12-lead ECGs. J Cardiovasc Magn Reson. 2013; 15(suppl 1):W20.

13. Kahlert P, Parohl N, Albert J, Schafer L, Reinhardt R, Kaiser GM, McDougall Decker B, Plicht B, Erbel R, et al. Real-time magnetic resonance imagingguided transarterial aortic valve implantation: in vivo evaluation in swine. J Am Coll Cardiol. 2012; 59:192-3.

14. Aneja A, Ono C, Scandling D, Jin N, Hinton AM, Pennell M, Raman SV, Simonetti OP. Left ventricular function, aortic velocity, and late gadolinium enhancement assessed by real-time and single shot CMR is comparable to breath-held segmented imaging: a prospective study. J Cardiovasc Magn Reson. 2013; 15(suppl 1):O51.

15. Gamper U, Boesiger $P$, Kozerke $S$. Compressed sensing in dynamic MRI. Magn Reson Med. 2008; 59:365-73.

16. Schmidt M, Ekinci O, Liu J, Lefebvre A, Nadar MS, Mueller E, Zenge MO. Novel highly accelerated real-time CINE-MRI featuring compressed sensing with k-t regularization in comparison to TSENSE segmented and real-time Cine imaging. J Cardiovasc Magn Reson. 2013; 15(suppl 1):P36.

17. Jogiya R, Kozerke S, Morton G, De Silva K, Redwood S, Perera D, Nagel E, Plein S. Validation of dynamic 3-dimensional whole heart magnetic resonance myocardial perfusion imaging against fractional flow reserve for the detection of significant coronary artery disease. J Am Coll Cardiol. 2012; 60:756-65.

18. Chen X, Salerno M, Epstein FH. Accelerated first-pass perfusion CMR using compressed sensing with regional spatiotemporal sparsity. J CardiovasC Magn Reson. 2013; 15(suppl 1):E16.

19. Tsao J. Ultrafast imaging: principles, pitfalls, solutions, and applications. J Magn Reson Imaging. 2010; 32:252-66.

20. Sharif B, Dharmakumar R, Arsanjani R, Thomson LE, Merz NB, Berman DS, Li D. Ungated cine first-pass CMR for concurrent imaging of myocardial perfusion defects and wall motion abnormalities. J Cardiovasc Magn Reson. 2013; 15(suppl 1):01.

21. Yang $Y$, Feng $X$, Meyer $C H$, Kramer CM, Salerno M. First-pass myocardial perfusion imaging with whole ventricular coverage using L1-SPIRIT accelerated spiral trajectories. J Cardiovasc Magn Reson. 2013; 15(suppl 1):P20.

22. Petersson S, Sigfridsson A, Carlhall CJ, Ebbers T. Retrospectively gated intra-cardiac 4D flow CMR using spiral k-space trajectories. J CardiovasC Magn Reson. 2013; 15(supll 1):064.

23. Biglands JD, Radjenovic A, Ridgway JP. Cardiovascular magnetic resonance physics for clinicians: part II. J Cardiovasc Magn Reson. 2012; 14:66. 
24. Sharif B, Dharmakumar R, LaBounty T, Shufelt C, Thomson LE, Merz NB, Berman DS, Li D. Eliminating dark-rim artifacts in first-pass myocardial perfusion imaging. J Cardiovasc Magn Reson. 2013; 15(suppl 1):O3.

25. Wu Y, Yang F, Chung Y-C. Robust and fast SSFP for the evaluation of LV function at 3T. J CardiovasC Magn Reson. 2013; 15(suppl 1):O52.

26. Rothstein T, Camargo GC, Quintella DC, Fernandes E, Strecker R, Greiser A, Derenne ME, Lima M, Moojen JJ, Rizzi PB, et al. Artifact suppression of SSFP cine sequences at 3T using a novel automatic 3D shimming algorithm. J Cardiovasc Magn Reson. 2013; 15(suppl 1):P57.

27. White SK, Sado DM, Flett AS, Moon JC. Characterising the myocardial interstitial space: the clinical relevance of non-invasive imaging. Heart 2012; 98:773-9.

28. Fitts M, Breton E, Kholmovski E, Dosdall DJ, Vijayakumar S, Hong KP, Ranjan R, Marrouche NF, Axel L, Kim D. Arrhythmia insensitive rapid cardiac T1 mapping pulse sequence. J Cardiovasc Magn Reson. 2013; 15(suppl 1):0112

29. Slavin GS, Stainsby JA. True T1 mapping with SMART1Map (saturation method using adaptive recovery times for cardiac T1 mapping): a comparison with MOLLI. J Cardiovasc Magn Reson. 2013; 15(suppl 1):P3.

30. Piechnik SK, Ferreira VM, Dall'Armellina E, Cochlin LE, Greiser A, Neubauer S, Robson MD. Shortened modified look-locker inversion recovery (ShMOLLI) for clinical myocardial T1-mapping at 1.5 And 3 T within a 9 heartbeat breathhold. J Cardiovasc Magn Reson. 2010; 12:69.

31. Henningsson $M$, Botnar RM, Voigt T. 3D saturation recovery imaging for free breathing myocardial T1 mapping. J Cardiovasc Magn Reson. 2013; 15(suppl 1):P44

32. Biglino G, Verschueren P, Zegels R, Taylor AM, Schievano S. Rapid prototyping compliant arterial phantoms for in-vitro studies and device testing. J Cardiovasc Magn Reson. 2013; 15:2.

33. Acevedo-Bolton G, Saloner D. Using MRI derived patient-specific flow models and flow imaging for flow diverting stent rehearsal. $J$ Cardiovasc Magn Reson. 2013; 15(suppl 1):056.

34. Jiji RS, Pollak AW, Epstein FH, Antkowiak PF, Meyer CH, Weltman AL, Lopez D, Dimaria JM, Hunter JR, Christopher JM, Kramer CM. Reproducibility of rest and exercise stress contrast-enhanced calf perfusion magnetic resonance imaging in peripheral arterial disease. J Cardiovasc Magn Reson. 2013; 15:14.

35. Clement-Guinaudeau S, Topel ML, Ali A, Poole JC, Rocco E, Khan SA, Zhong X, Epstein FH, Kramer CM, Quyyumi AA, Oshinski JN. MR-based calf muscle perfusion index correlates with treadmill exercise test parameters in patients with peripheral arterial disease. J Cardiovasc Magn Reson. 2013; 15(suppl 1):058

36. Bruder O, Wagner A, Lombardi M, Schwitter J, van Rossum A, Pilz G, Nothnagel D, Steen H, Petersen S, Nagel E, et al. European cardiovascular magnetic resonance (EuroCMR) registry - multi national results from 57 centers in 15 countries. J Cardiovasc Magn Reson. 2013; 15:9.

37. Andre F, Celik C, Abdel-Aty H, Santos MFB, Giannitsis E, Katus H, Steen H. Comparison of parameters for left ventricular volumes and function between echocardiography and cardiovascular magnetic resonance in a large group of cardiac patients. J Cardiovasc Magn Reson. 2013; 15(suppl 1):E74.

38. Joshi SB, Connelly KA, Jimenez-Juan L, Hansen M, Kirpalani A, Dorian P, Mangat I, Al-Hesayen A, Crean AM, Wright GA, et al. Potential clinical impact of cardiovascular magnetic resonance assessment of ejection fraction on eligibility for cardioverter defibrillator implantation. J Cardiovasc Magn Reson. 2012; 14:69.

39. Wong TC, Piehler K, Puntil KS, Moguillansky D, Meier CG, Lacomis JM, Kellman P, Cook SC, Schwartzman DS, Simon MA, et al. Effectiveness of late gadolinium enhancement to improve outcomes prediction in patients referred for cardiovascular magnetic resonance after echocardiography. J Cardiovasc Magn Reson. 2013; 15:6.

40. Assomull RG, Shakespeare C, Kalra PR, Lloyd G, Gulati A, Strange J, Bradlow WM, Lyne J, Keegan J, Poole-Wilson P, et al. Role of cardiovascular magnetic resonance as a gatekeeper to invasive coronary angiography in patients presenting with heart failure of unknown etiology. Circulation. 2011; 124:1351-60.

41. Greenwood JP, Maredia N, Younger JF, Brown JM, Nixon J, Everett CC, Bijsterveld P, Ridgway JP, Radjenovic A, Dickinson CJ, et al. Cardiovascular magnetic resonance and single-photon emission computed tomography for diagnosis of coronary heart disease (CE-MARC): a prospective trial. Lancet. 2012; 379:453-60.

42. Greenwood JP, Walker S, Giardin F, McKenna C, Everett C, Nixon J, Brown J, Plein MS. Cost-effectiveness of magnetic resonance imaging in coronary heart disease: an economic evaluation using data from the CE-MARC study. J Cardiovasc Magn Reson. 2013; 15(suppl 1):07.

43. Kelle S, Petrov G, Kern S, Fleck E, Wellnhofer E. Cost-effectiveness of dobutamine stress cardiac magnetic resonance imaging in stable coronary artery disease - a post-hoc analysis. J Cardiovasc Magn Reson. 2013; 15(suppl 1):O8.

44. Genders TS, Petersen SE, Pugliese F, Dastidar AG, Fleischmann KE, Nieman K, Hunink M. Stress myocardial perfusion cardiac magnetic resonance imaging vs. coronary CT angiography in the diagnostic work-up of patients with stable chest pain: comparative effectiveness and costs. J Cardiovasc Magn Reson. 2013; 15(suppl 1):O9.

45. Plein S, Herzog BA, Maredia N, Kidambi A, Motwani M, Uddin A, Ripley DP, Dickinson CJ, Brown J, Nixon J, et al. The ischaemic and scar burden measured by cardiac magnetic resonance imaging in patients with ischaemic coronary heart disease from the CE-MARC study. J CardiovasC Magn Reson. 2013; 15(suppl1):0105.

46. Manka R, Gebker R, Wissmann L, Jogiya R, Motwani M, Frick M, Reinartz SD, Schnackenburg B, Nagel E, Plein S, Kozerke S. Multicenter evaluation of dynamic three-dimensional whole-heart myocardial perfusion imaging for the detection of coronary artery disease defined by fractional flow reserve. J Cardiovasc Magn Reson. 2013; 15(suppl 1):0103.

47. Parsai C, O'Hanlon R, Prasad SK, Mohiaddin RH. Diagnostic and prognostic value of cardiovascular magnetic resonance in non-ischaemic cardiomyopathies. J Cardiovasc Magn Reson. 2012; 14:54.

48. Maron MS. Clinical utility of cardiovascular magnetic resonance in hypertrophic cardiomyopathy. J Cardiovasc Magn Reson. 2012; 14:13.

49. Ismail TF, Jabbour A, Gulati A, Mallorie A, Raza S, Cowling TE, Das B, Khwaja J, Wage R, Moon J, et al. Late gadolinium enhancement cardiovascular magnetic resonance for sudden cardiac death risk stratification in hypertrophic cardiomyopathy. J Cardiovasc Magn Reson. 2013; 15(suppl 1):067

50. Noureldin RA, Liu S, Nacif MS, Judge DP, Halushka MK, Abraham TP, Ho C, Bluemke DA. The diagnosis of hypertrophic cardiomyopathy by cardiovascular magnetic resonance. J Cardiovasc Magn Reson. 2012; 14:17.

51. Deva DP, Williams LK, Care M, Siminovitch KA, Moshonov H, Wintersperger BJ, Rakowski H, Crean AM. Incremental predictive value of deep crypts in the basal inferoseptum in the setting of hypertrophic cardiomyopathy. J Cardiovasc Magn Reson. 2013; 15(suppl 1):033.

52. Flett A, Maestrini V, Milliken D, Fontana M, Harb R, Sado D, Quarta G, Herrey AS, Elliott P, McKenna WJ, Moon J. A new variant of apical hypertrophic cardiomyopathy? T wave inversion and relative but not absolute apical left ventricular hypertrophy. J Cardiovasc Magn Reson. 2013; 15(suppl 1):036.

53. Sado DM, White SK, Piechnik SK, Banypersad SM, Treibel T, Captur G, Fontana M, Maestrini V, Flett AS, Robson MD, et al. Identification and assessment of anderson-fabry disease by cardiovascular magnetic resonance noncontrast myocardial t1 mapping. Circ Cardiovasc Imaging. 2013; 6:392-8

54. Simpson R, Keegan J, Firmin D. Efficient and reproducible high resolution spiral myocardial phase velocity mapping of the entire cardiac cycle. J Cardiovasc Magn Reson. 2013; 15:34.

55. Alexandre J, Saloux E, Dugue AE, Lebon A, Lemaitre A, Roule V, Labombarda F, Provost N, Gomes S, Scanu P, Milliez P. Scar extent evaluated by late gadolinium enhancement CMR: a powerful predictor of long term appropriate ICD therapy in patients with coronary artery disease. J Cardiovasc Magn Reson. 2013; 15:12

56. Leyva F, Foley PW, Chalil S, Ratib K, Smith RE, Prinzen F, Auricchio A. Cardiac resynchronization therapy guided by late gadolinium-enhancement cardiovascular magnetic resonance. J Cardiovasc Magn Reson. 2011; 13:29.

57. Tse Z, Dumoulin C, Byrd I, Schweitzer J, Watkins R, Pauly KB, Kwong RY, Michaud GF, Stevenson W, Jolesz F, Schmidt EJ. Voltage-based electroanatomic mapping system for MR-guided cardiac electrophysiology: preliminary swine validations. I Cardiovasc Magn Reson. 2013; 15(suppl 1):088.

58. Ramanan V, Celik H, Ghate S, Barry J, Ghugre NR, Leber V, Stainsby JA, Shmatukha A, Shurrab M, Crystal E, Wright G. Exploring intrinsic MR signal relaxation in acute RF ablation lesions using $\mathrm{T} 2$ mapping and IR-SSFP CINE imaging. J Cardiovasc Magn Reson. 2013; 15(suppl 1):087.

59. Ainslie M, Miller CA, Brown B, Davidson N, Fox DJ, Schmitt M. Multiparametric CMR assessment of RV apical versus septal Pacing Study (MAPS) - preliminary acute hemodynamic findings. J Cardiovasc Magn Reson. 2013; 15(suppl 1):085. 
60. Muzzarelli S, Monney P, O'Brien K, Faletra F, Moccetti T, Vogt P, Schwitter J. Quantification of aortic valve regurgitation by phase-contrast magnetic resonance in patients with bicuspid aortic valve: where to measure the flow? J Cardiovasc Magn Reson. 2013; 15(suppl 1):O37.

61. Hart C, Gabbert DD, Voges I, Jerosch-Herold M, Andrade A, Pham M, Hansen T, Kramer H-H, Rickers C. New insights in the Fontan circulation: 4-dimensional respiratory- and ECG-triggered phase contrast magnetic resonance imaging. J Cardiovasc Magn Reson. 2013; 15(suppl 1):O38.

62. Markl M, Kilner PJ, Ebbers T. Comprehensive $4 \mathrm{D}$ velocity mapping of the heart and great vessels by cardiovascular magnetic resonance. J Cardiovasc Magn Reson. 2011; 13:7.

doi:10.1186/1532-429X-15-60

Cite this article as: Carpenter et al:: Highlights of the 16th annual scientific sessions of the Society for Cardiovascular Magnetic Resonance. Journal of Cardiovascular Magnetic Resonance 2013 15:60.

\section{Submit your next manuscript to BioMed Central and take full advantage of:}

- Convenient online submission

- Thorough peer review

- No space constraints or color figure charges

- Immediate publication on acceptance

- Inclusion in PubMed, CAS, Scopus and Google Scholar

- Research which is freely available for redistribution 